\title{
Mercury-associated DNA hypomethylation in polar bear brains via the LUminometric Methylation Assay: a sensitive method to study epigenetics in wildlife
}

\author{
J. RICHARD PILSNER,* ALICIA L. LAZARUS, * DONG-HA NAM,† ROBERT J. LETCHER, \\ CHRISTIAN SONNE, $\$$ RUNE DIETZ§ and NILADRI BASU† \\ *Department of Epidemiology, +Department of Environmental Health Sciences, School of Public Health, University of Michigan, \\ Ann Arbor, MI 48109, USA, $\ddagger$ Environment Canada, National Wildlife Research Center, Carleton University, Ottawa, ON K1A \\ 0H3, Canada, §National Environmental Research Institute, University of Aarhus, Frederiksborgvej 399, DK-4000 Roskilde, \\ Denmark
}

\begin{abstract}
In this paper we describe a novel approach that may shed light on the genomic DNA methylation of organisms with non-resolved genomes. The LUminometric Methylation Assay (LUMA) is permissive for genomic DNA methylation studies of any genome as it relies on the use of methyl-sensitive and -insensitive restriction enzymes followed by polymerase extension via Pyrosequencing technology. Here, LUMA was used to characterize genomic DNA methylation in the lower brain stem region from 47 polar bears subsistence hunted in central East Greenland between 1999 and 2001. In these samples, average genomic DNA methylation was $57.9 \% \pm 6.69$ (SD; range was 42.0 to $72.4 \%$ ). When genomic DNA methylation was related to brain mercury $(\mathrm{Hg})$ exposure levels, an inverse association was seen between these two variables for the entire study population ( $P$ for trend $=0.17$ ). After dichotomizing animals by gender and controlling for age, a negative trend was seen amongst male animals ( $P$ for trend $=0.07$ ) but no associations were found in female bears. Such sexually dimorphic responses have been found in other toxicological studies. Our results show that genomic DNA methylation can be quantitatively studied in a highly reproducible manner in tissue samples from a wild organism with a non-resolved genome. As such, LUMA holds great promise as a novel method to explore consequential questions across the ecological sciences that may require an epigenetic understanding.
\end{abstract}

Keywords: DNA methylation, ecotoxicology, epigenetics, neurotoxicology, wildlife

Received 5 August 2009; revision accepted 22 October 2009

\section{Introduction}

Mercury $(\mathrm{Hg})$ is a pollutant of particular concern to the Arctic ecosystem and human health (Dietz et al. 1998). Released mainly as a by-product of coal burning in southern latitudes, Mercury is atmospherically transported to the Arctic where it biomagnifies in food chains. Polar bears, as apex predators, accumulate mercury at concentrations known to harm other animals (Basu et al. 2009). Mercury is a potent neurotoxin that

Correspondence: Niladri Basu, Fax: 1734936 7283;

E-mail: niladri@umich.edu impacts the ability of animals to sense and respond to environmental change (Clarkson \& Magos 2006). For example, mercury-polluted fish (Hontela et al. 1992) and birds (Franceschini et al. 2009) have an impaired ability to cope with subsequent exposures to ecological stressors. Polar bears are considered to be one of the most sensitive species to climate change (Laidre et al. 2008), and with levels of mercury increasing in many regions of the Arctic the potential exists for this heavy metal to impair the ability of polar bears to cope with and adapt to the added stress of climate change. Although it is difficult to experimentally resolve the precise mechanism(s) that may underlie mercury-induced 
impaired coping abilities in wildlife, these are likely influenced by a combination of intrinsic biological properties and several external environmental factors.

The interaction of environmental signals (i.e. chemical stressors such as mercury) and gene expression may be realized at the level of the epigenome. DNA methylation is the most widely studied of the known epigenetic marks and plays important roles in transcriptional regulation, X chromosome inactivation, embryonic development, imprinting, suppression of parasitic DNA sequences, and maintenance of genomic stability (Jaenisch \& Bird 2003; Jirtle \& Skinner 2007). Aberrant DNA methylation patterning, such as gene-specific hypermethylation and genomic hypomethylation, is associated with numerous human diseases, including neurological disorders (Mill et al. 2008; Wang et al. 2008) and cancers (Esteller 2008). DNA methylation occurs on the 5 carbon of cytosine and almost exclusively within $\mathrm{CpG}$ dinucleotides. The bulk of methylated CpG dinucleotides are located within simple repeat sequences, such as DNA satellites and transposons. Although the biological significance of changes in genomic methylcytosine content is less understood than gene-specific methylation, maintenance of homeostatic levels of genomic DNA is thought to play a critical role in genomic defence and structural integrity by silencing expression of transposable elements, thereby limiting chromosomal rearrangements and translocations (Wilson et al. 2007). Accordingly the epigenome is emerging as an important entity involved in key mechanisms that underlie the health of individuals and ecosystems, though few have investigated epigenetics in the natural sciences.

Chemical pollutants are a relevant class of ecological stressor that can impact DNA methylation status. In vitro biomedical studies using rodent models have shown that several heavy metals impair DNA methyltransferase activity and disrupt DNA methylation status (Chen et al. 2006; Reichard et al. 2007; Jiang et al. 2008; Sun et al. 2009). Human epidemiological studies have documented that exposure to arsenic (Chen et al. 2004; Pilsner et al. 2007), lead (Pilsner et al. 2009) and persistent organic pollutants (Rusiecki et al. 2008) may also be associated with alterations in genomic DNA methylation. As epigenetic signals can be inherited, there is potential for chemical pollutants to cause long-term, transgenerational effects. For example, in a series of studies on the fungicide vinclozolin, exposure of F0 generation rats resulted in a series of disease states (e.g. increased tumour development, kidney disease, spermatogenic outcomes) in F1-F4 generation offspring that were associated with alterations in DNA methylation of the male germ line (Anway et al. 2005; Chang et al. 2006). Accordingly chemically-induced changes in DNA methylation may have long-term consequences to population health.

Though an epigenetic understanding may resolve consequential questions across the ecological sciences, epigenetic studies of natural wildlife populations has been challenging due to the lack of sensitive and quantitative assays to study genomes that are largely undefined. In this paper we describe a novel approach that may shed light on the genomic DNA methylation of organisms with non-resolved genomes. The LUminometric Methylation Assay (LUMA) is permissive for genomic DNA methylation studies of any genome as it relies on the use of methyl-sensitive and -insensitive restriction enzymes followed by polymerase extension via Pyrosequencing technology (Karimi et al. 2006b). Here we used LUMA to characterize genomic DNA methylation in the polar bear lower brain stem region. We then related brain DNA methylation status with exposure of these bears to mercury under the hypothesis that DNA methylation status will vary across these animals in a concentration dependent manner.

\section{Materials and methods}

\section{Animals and tissues}

In collaboration with local subsistence Inuit hunters, medulla oblongata (lower portion of the brain stem) tissue was obtained from polar bears in the Ittoqqortoormiit/Scoresby Sound area in central East Greenland between 1999 and 2001 as described earlier (Basu et al. 2009). All tissues were collected within $12 \mathrm{~h}$ postmortem and stored frozen until DNA extraction. Concentrations of mercury were measured at an accredited laboratory for metals analyses (National Wildlife Research Centre, Environment Canada) using a direct mercury analyzer (AMA-254, Altec, Czech Republic) as previously described (Basu et al. 2009). In an earlier study no striking relationships were found between mercury levels and concentrations of several persistent organic pollutants in the polar bear brain (Basu et al. 2009). Age was determined by counting the dental cementum growth layers (Dietz et al. 1991).

\section{DNA processing}

Though 82 polar bears were initially collected for our larger study, this paper is focused on samples from 47 polar bears which yielded DNA of high quantity and quality. Genomic DNA was isolated and stored $\left(-20^{\circ} \mathrm{C}\right)$ using QIAamp DNA Mini Kit as per manufacturer's protocols. The purified DNA (A260/A280 ratio of $1.7-2.0$ ) was predominately $20-30 \mathrm{~kb}$ in size, with a range upwards of $50 \mathrm{~kb}$. Since the LUMA assay relies 
on the recognition and subsequent cleavage of doublestranded DNA, we also used Quant-iT Picogreen Assay Kit (Invitrogen) which quantifies double-stranded DNA. The $R^{2}$ for DNA concentrations between spectrophotometry and Picogreen was 0.75. The Picogreen assay was employed as suggested by the manufacture's protocol.

\section{LUMA assay}

The LUminometric Methylation Assay (LUMA) has been used for studying genomic DNA methylation in humans, and here we adapt and optimize the method for studying DNA methylation in tissues from organisms with non-resolved genomes. The LUMA method has been described in-depth by Ekstrom and colleagues (Karimi et al. 2006a,b). Briefly, LUMA is based on recognition and cleavage of $5^{\prime}$-CCGG-3' sequences by the methylation sensitive restriction enzyme (HpaII) and its methylation insensitive isoschizomer $(\mathrm{Mspl})$ in parallel reactions (Karimi et al. 2006b). Additionally, EcoRI is included in all reactions to normalize the amount of DNA input. HpaII and MspI both produce 5'-CG overhangs after restriction cleavage, whereas EcoRI produces 5'-AATT overhangs. The extent of restriction cleavage is then measured by bioluminometic polymerase extension via Pyrosequencing (Qiagen). The method is quantitative, highly reproducible and uses an internal control for DNA input.

For each sample, genomic DNA (300 ng) was digested with HpaII + EcoRI and MspI + EcoRI in parallel reactions containing $2 \mu \mathrm{L}$ of Tango buffer (Fermentas), $5 \mathrm{U}$ of HpaII or MspI, $5 \mathrm{U}$ of EcoRI and $\mathrm{dH}_{2} \mathrm{O}$ to a final volume of $20 \mu \mathrm{L}$. Samples were incubated at $37^{\circ} \mathrm{C}$ for $4 \mathrm{~h}$. After the incubation, $15 \mu \mathrm{L}$ of Pyrosequencing annealing buffer (Qiagen) was added to samples. After mixing, $30 \mu \mathrm{L}$ of the sample reaction containing the annealing buffer was transferred to 96 well Pyrosequencing plates. The original LUMA assay has been modified by changing nucleotide-dispensing order with a series of dTTPs and dGTPs before measurement to eliminate any background caused by any non-digestion 5 ' overhangs that could occur during DNA purification (Bjornsson et al. 2008). The following nucleotide dispensation order was used: GTGTCACATGTGTG; where the first two dGTPs and dTTPs are used to eliminate background, the first two dCTPs and dATPs to fill the first nucleotides produced by HpaII/MspI and EcoRI, respectively, and finally, dTTPs and dGTPs to finish the polymerase extensions of EcoRI and HpaII/MspI, respectively.

Peak heights of nucleotide incorporation from the resulting pyrograms were used to calculate $\%$ genomic DNA methylation using the formula: 1-[(HpaII $(\mathrm{G}) /$
$\operatorname{EcoRI}(\mathrm{T})) /(\operatorname{MspI}(\mathrm{G}) / \operatorname{EcoRI}(\mathrm{T}))] \times 100$, where $\mathrm{G}$ and $\mathrm{T}$ are the peak heights for HpaII or MspI (methylation) and EcoRI (input DNA), respectively. Samples that were not of high molecular weight (degraded DNA), as determined by gel electrophoresis, were excluded. Additionally, samples of low DNA concentration which did not have a HpaII(G) peak heights $>10$ units from the LUMA assay were found to be unreproducible and were excluded from this study. All samples were run in duplicate. The intra- and interday coefficient of variation of remaining samples was $0.55 \%$ and $3.01 \%$, respectively.

\section{Statistics}

Data were analyzed using SAS 9.1 (SAS Institute Inc. 2002-2003). Samples $(N=35)$ with a 'G-peak' from the HpaII/EcoRI reaction $<10$ relative units obtained from LUMA pyrograms were excluded due to the lack of $\%$ DNA methylation reproducibility Brain mercury and DNA methylation were checked for normality and were found to be normally distributed. The relationship between brain mercury and percentage DNA methylation was analyzed with linear regression. Mercury quartiles were established using the median and the $25 \%$ and $75 \%$ interquartile mercury cutoffs and were then used to determine the trends between quartiles of mercury measures and percent DNA methylation, as a continuous variable. Age was used as a co-variate in some models, as indicated, for gender-specific effects of mercury and DNA methylation, models were dichotomized by gender.

\section{Results}

An example of two resulting LUMA pyrograms using genomic DNA from polar bear brain stem tissue is shown in Fig. 1. For each sample, two reactions (HpaII $+E c o R I$ and MspI + EcoRI) are run in parallel to determine genomic DNA methylation, where the $3^{\text {rd }} \mathrm{dGTP}$ dispensation ( $10^{\text {th }}$ total nucleotide dispensation) is used to measure the percent of DNA methylation between HpaII and MspI digestions. Since MspI is a methylinsensitive restriction enzyme, the dGTP peak in Fig. 1b is used to estimate the total number of CCGG sites within the polar bear genome. Conversely, while HpaII is a methyl-sensitive restriction enzyme, the dGTP peak observed in Fig. 1a corresponds to the extent of unmethylated CCGG sequences. Thus, HpaII/MspI ratio can be used to estimate the percent CpG DNA methylation within the context of CCGG sequences. Furthermore, the addition of EcoRI in each reaction is used to measure the amount of input DNA ( $3^{\text {rd }}$ dTTP and $9^{\text {th }}$ total nucleotide dispensation) and thus allows the normalization of 

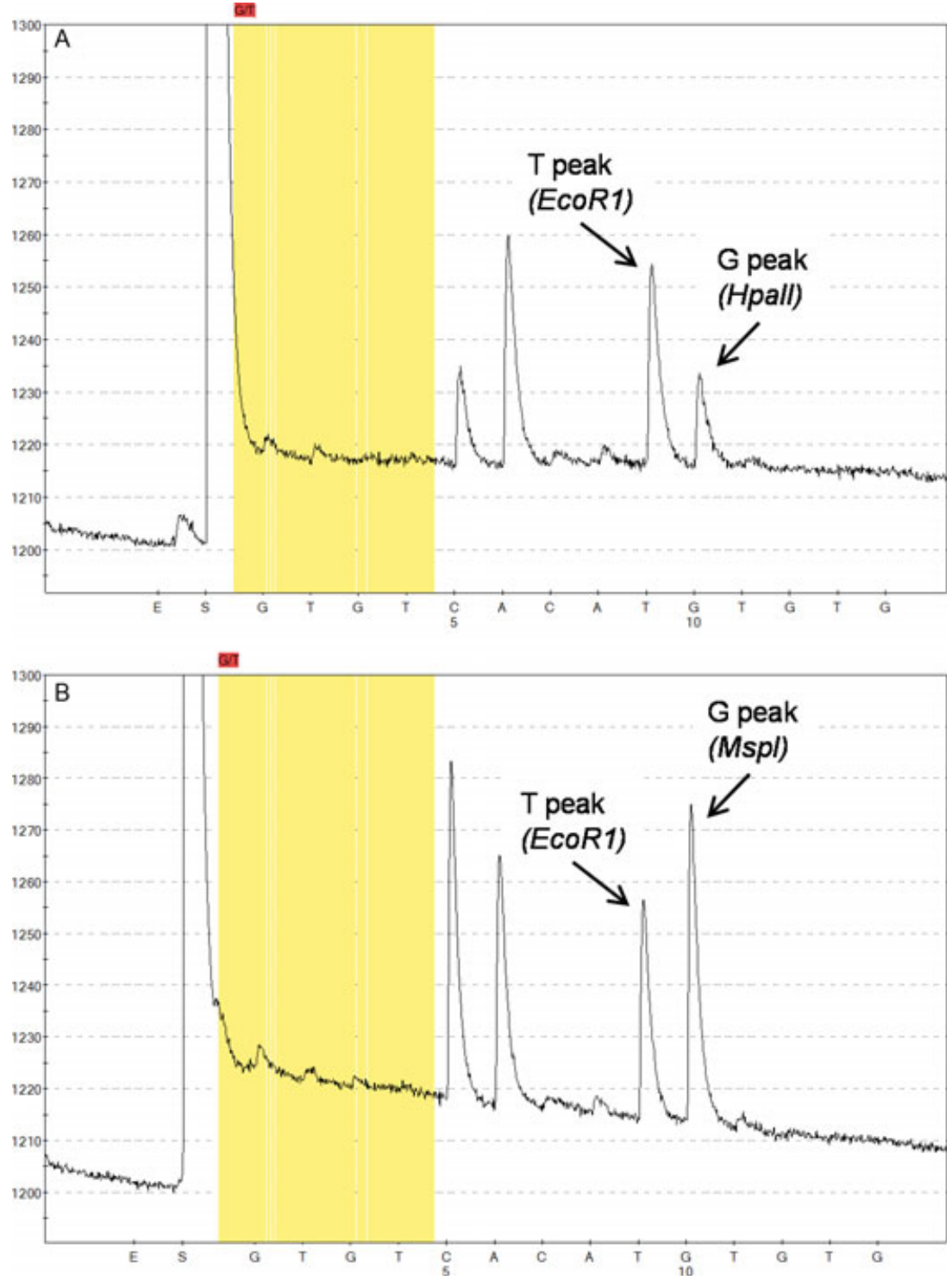

Fig. 1 Representative pyrograms from LUMA using control polar bear brain stem DNA. The $y$-axis is the intensity of luminometric detection corresponding to the amount of dNTP incorporation, whereas the $x$-axis displays the dispensation of nucleotides. A. Pyrogram for HpaII/EcoRI digestion. B. Pyrogram for MspI/EcoRI digestion.

DNA concentrations across reactions. Finally, we also employed a series of dGTP and dTTP dispensations in the beginning of the Pyrosequencing reaction to eliminate any background polymerase extension caused by non-digested 5 'overhangs To demonstrate linearity of LUMA, mixing experiments were first conducted using methylated (Sss1 treated) and unmethylated lambda DNA; the assay was linear at the range of $0 \%$ to $100 \%$ methylation $\left(R^{2}=0.981\right)$.

Table 1 provides the characteristics of the 47 polar bears in which high quality DNA was obtained. Brain mercury concentrations averaged $0.37 \pm 0.16 \mathrm{ppm}$ (dry weight) and ranged from 0.11 to $0.73 \mathrm{ppm}$. The average age, as estimated by counting cementum growth layers was 6.5 years and ranged from 2 to 22 years with $70.2 \%$ of animals considered sub adults (2-6 years of age) and $29.8 \%$ defined as adults ( $>6$ years of age). The average genomic DNA methylation, as measured by LUMA, was $57.85 \% \pm 6.62$ (SD) and ranged from 42.0 to $72.4 \%$.

When genomic DNA methylation was related to mercury exposure, an inverse association was seen between brain mercury levels and genomic DNA methylation for the entire study population in unadjusted models ( $P$ for trend $=0.17$; Fig. 2). After dichotomizing animals by gender and controlling for age, a clearer trend was seen 
Table 1 Characteristics of study population

\begin{tabular}{lcr}
\hline Variable & Mean \pm SD & \multicolumn{1}{c}{ Range } \\
\hline Brain mercury $(\mathrm{ppm})$ & $0.37 \pm 0.16$ & $0.11-0.73$ \\
Age (years; $N=46)$ & $6.5+5.0$ & $2.0-22.0$ \\
Sub-adults $[N(\%)]$ & $33(71.7)$ & \\
Adults $[N(\%)]$ & $13(28.3)$ & \\
\hline
\end{tabular}

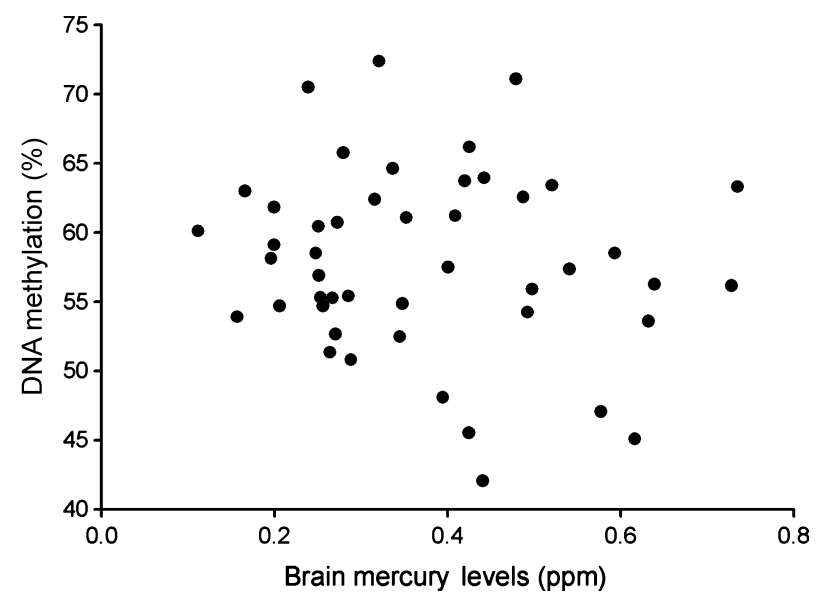

Fig. 2 Scatter plot depicting polar bear brain mercury concentrations (ppm) and DNA methylation (\%) among the study population $(N=47)$.

between quartiles of mercury exposure and mean levels of genomic DNA methylation amongst male animals $(N=26$; $P$ for trend $=0.07$; Fig. 3$)$. The mean group difference between the lowest and highest quartile was $6.4 \%$ when controlling for age $(P=0.11)$. For female animals, there was no concentration-dependent relationship $(N=21 ; P$ for trend $=0.47$; Fig. 3 ), and there was no association found between age, either as a continuous or categorical variable, and genomic DNA methylation (data not shown).

\section{Discussion}

The outcome of our study shows that LUMA holds great promise as a novel method to study DNA methylation in organisms with a non-resolved genome. This is achieved in a manner that is highly quantitative and reproducible. Using LUMA, here we showed an inverse association between mercury exposure and DNA methylation in the lower brain stem of male polar bears. That mercury-associated DNA hypomethylation was restricted to male bears is not surprising as laboratory studies have previously reported sexually dimorphic effects (Anway et al. 2005; Chang et al. 2006). While studies on phenotypic change and transgenerational impacts were not feasible aims in the present ecological
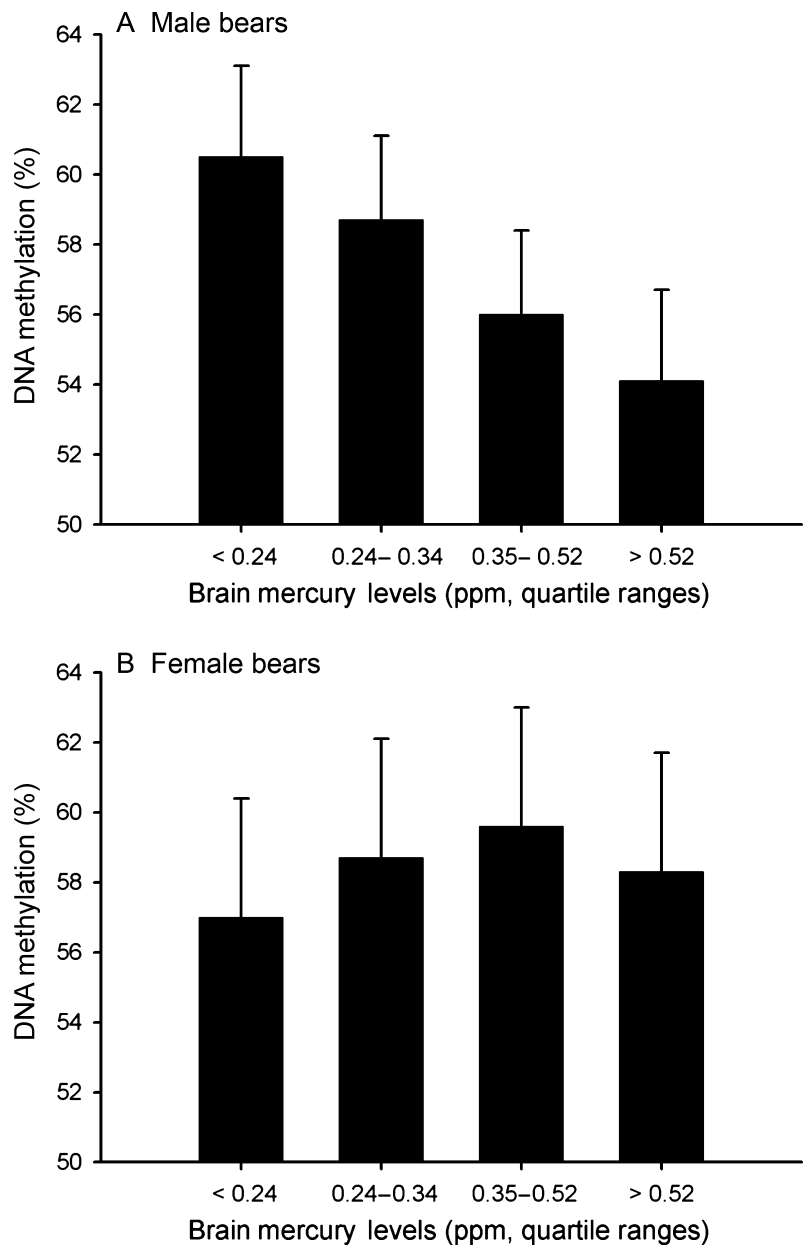

Fig. 3 DNA methylation (\%) by quartiles of mercury exposure stratified by gender and controlling for age. A: Male: $N=26$; $\mathrm{Q} 1, N=6: \mathrm{Q} 2, N=7: \mathrm{Q} 3, N=7: \mathrm{Q} 4, N=6 ; P$ for trend = 0.07; B: Female: $N=20(\mathrm{Q} 1-\mathrm{Q} 4, N=5) ; P$ for trend $=0.43$.

study, aberrant changes to DNA hypomethylation have been linked to long-term changes in chromosomal stability, disease progression, and reproductive function (Dolinoy et al. 2006; Jirtle \& Skinner 2007). This is of particular concern to the polar bear which last year was listed as 'threatened' under the U.S. Endangered Species Act (USFWS 2008).

Epigenetic approaches are gaining popularity in the ecological sciences. In a study of 42 vertebrates, Jabbari et al. (1997) characterized 5-methylcytosine content and GC levels using high performance liquid chromatography (HPLC). In a series of studies by Vandegehuchte et al. $(2009 \mathrm{a}, \mathrm{b})$ concerned with multigenerational metals exposures in Daphnia magna, the overall content of genomic 5-methyl-2'-deoxycytidine $(5 \mathrm{mdC})$ was assayed using mass spectroscopy. The LUMA assay we describe here moves beyond these aforementioned approaches as it yields quantitative results that are highly reproducible 
in a high throughput and rapid manner. After the initial $4 \mathrm{~h}$ of restriction digestion of DNA, 96 reactions (48 samples; one well for HpaII + EcoRI and one well for $M s p I+E c o R I)$ can be analyzed simultaneously using Pyrosequencing technology in less than 20 min. Finally, the modified LUMA assay eliminates any non-specific restriction extension as a result of DNA degradation by employing a series of dGTP and dTTP dispensations in the beginning of the Pyrosequencing reaction (Bjornsson et al. 2008). However, it must be noted that a limitation to the LUMA assay is the inability to measure total cytosine methylation within the genome, as is achieved by HPLC or mass spectroscopy since restriction digestion is limited to $\mathrm{CpG}$ methylation within CCGG sequences. Despite this limitation, the LUMA assay has been able to detect intra-individual changes in DNA methylation overtime (Bjornsson et al. 2008) and methylation differences in cell lines with DNA methyltransferase knockouts (Karimi et al. 2006b). Here we show that LUMA can be adapted for the study of organisms with non-resolved genomes rendering it a method with potentially broad applications to the natural sciences.

In a study on several organisms, the percent of cytosines that were methylated was twice that in fish and amphibians as compared to birds, reptiles, and mammals ( $9 \%$ vs. $4.5 \%$, respectively) even though the average GC content (42.5\%) was similar across species (Jabbari et al. 1997). This finding is in agreement with other estimates of the percent of cytosines that are methylated in mammals (3-6\%), whereby $70 \%$ of cytosines within CpG dinucleotides are methylated (Robertson \& Wolffe 2000; Esteller 2007). In our study, the average methylation of brain stem DNA (i.e. CpG sites) among polar bears was $57.9 \%$, ranging from $42.0 \%$ to $72.4 \%$, and this was lower than expected for mammals (estimated human LUMA's values of 72-75\%; unpublished data, J.R. Pilsner, University of Michigan, Ann Arbor). Moreover, the range of DNA methylation levels was also wider than anticipated. However, the varying degree of DNA methylation across samples is comparable to changes in LINE-1 methylation reported in tumours as compared to normal tissue (Choi et al. 2007). Interestingly, mapping of HpaII sites within the human genome revealed a 15-fold enrichment of 5'-CCGG-3' sites in CpG islands, potentially critical regulatory domains (Bjornsson et al. 2008). Thus, if such an enrichment of HpaII sites also exist in polar bears, mercury-associated DNA hypomethylation could have significant implications for gene regulation.

Increasing numbers of wildlife researchers are using DNA obtained from tissues of wild caught animals to study, for example, systematics, taxonomy, gender identification, and pathogen detection. Though, studying
DNA (and its methylation) from biological samples obtained from natural populations poses some challenges as tissues are rarely preserved optimally for molecular analysis of nucleic acids (i.e. sterile collection and immediate freezing). Here we found that DNA quality and quantity were adequate from 47 of 82 polar bears. It should be mentioned that our bear samples were frozen within 1-12 $\mathrm{h}$ of capture and that they were initially preserved and stored at $-20{ }^{\circ} \mathrm{C}$, and later at $-40{ }^{\circ} \mathrm{C}$ and $-80^{\circ} \mathrm{C}$. Human-based studies have shown that DNA is relatively stable postmortem, and that good quality DNA can be obtained from brain samples following postmortem delays of $72 \mathrm{~h}$ or more (Hynd et al. 2003). Ecological researchers have also verified the stability of DNA collected from wild populations (Smith \& Burgoyne 2004). A recent study found that DNA methylation was not impacted by postmortem changes in brain $\mathrm{pH}$ (Ernst et al. 2008) though more work is needed to assess the stability of methylated DNA especially under ecological conditions relevant to wildlife scientists. In respect to LUMA, DNA quality is an important aspect of assay reliability and reproducibility. Not surprising, we found that only nondegraded DNA samples of high molecular weight, as determined by DNA electrophoresis, produced quality pyrograms. We also found that the use of fluorescent stain specific for quantifying double-stranded DNA, such as Picogreen, more accurately reflected DNA concentrations compatible with LUMA (e.g. doublestranded DNA) as compared to spectrophotometry, especially in samples with $260 / 280$ ratios less than 1.8 (data not shown).

The levels of mercury we found in the polar bear brain stem were lower than brain levels reported in other piscivorous wildlife that bioaccumulate mercury (Basu et al. 2009) so future studies should investigate whether mercury-associated DNA hypomethylation is consistent across taxa. Though, examination of liver tissues from the same polar bears studied here (Sonne et al. 2007) and results from others (Dietz et al. 2000; Rush et al. 2008) reveal that the polar bear may naturally accumulate some of the highest mercury levels across any species. While we did not characterize DNA methylation in the liver, others have found methylation patterns to be consistent across different tissue types for a given species (Dolinoy et al. 2006; Eckhardt et al. 2006), and we speculate that our results in the brain may likely be similar in non-neural tissues. However, further investigation of the correlates between tissuetype must be pursued before any definitive answers are made.

Our data suggest sexual dimorphism in DNA methylation may also exist in response to mercury exposure, such that, mercury-associated DNA hypomethylation 
was observed only in males. The prevalence of a large amount of human diseases, such as atherosclerosis and autoimmune diseases (Ballestar et al. 2006; Gabory et al. 2009), displays sexual biases. There are many examples, from both wildlife (Orlando \& Guillette 2007) and human (Gochfeld 2007) studies, that toxic chemicals illicit sexually dimorphic effects. The epigenome can not only be influenced by environmental factors such as social behaviour, nutrition and chemical exposure, but also can be influenced by sex chromosomes and sex steroid hormones. Together, the complex interaction(s) between environmental challenges, sex chromosomes and sex steroid hormones is likely to cause gender-specific sensitivity to certain environmental challenges. In this context, it is plausible that epigenetic regulation among male polar bears is more susceptible to mercury exposure as compared to females.

In conclusion, our results show that the genomic DNA methylation can be quantitatively studied in a highly reproducible manner in tissue samples from a wild organism with a non-resolved genome. As such, LUMA holds great promise as a novel method to explore questions across the ecological sciences that may require an epigenetic understanding. Using LUMA we show mercury-associated DNA hypomethylation in the polar bear brain though further studies are required to validate this finding (e.g. other bear tissue types, additional wildlife species, laboratory evidence) and address its significance to ecology and physiology.

\section{Acknowledgements}

The authors would like to acknowledge the support of Della Bond, Jonas Brønlund, Robyn Ferguson, Maja Kirkegaard, Jeppe Møhl, Tony Scheuhammer, and the NWRC Specimen Bank staff. We acknowledge the support of various Greenlandic hunters and the Commission for Scientific Research in Greenland for facilitating the collection of polar bear tissue samples. This study was supported by Danish grants from the Cooperation for Environment in the Arctic, the Lundbeck Foundation, and the University of Michigan School of Public Health. No conflict of interest is declared, and the authors assume sole responsibility for the contents of this manuscript.

\section{References}

Anway MD, Cupp AS, Uzumcu M, Skinner MK (2005) Epigenetic transgenerational actions of endocrine disruptors and male fertility. Science, 308, 1466-1469.

Ballestar E, Esteller M, Richardson BC (2006) The epigenetic face of systemic lupus erythematosus. Journal of Immunoloogy, 176, 7143-7147.

Basu N, Scheuhammer AM, Sonne C et al. (2009) Is dietary mercury of neurotoxicological concern to wild polar bears (Ursus maritimus)? Environmental Toxicology and Chemistry, 28, 133-140.
Bjornsson HT, Sigurdsson MI, Fallin MD et al. (2008) Intraindividual change over time in DNA methylation with familial clustering. Journal of the American Medical Association, 299, 2877-2883.

Chang HS, Anway MD, Rekow SS, Skinner MK (2006) Transgenerational epigenetic imprinting of the male germline by endocrine disruptor exposure during gonadal sex determination. Endocrinology, 147, 5524-5541.

Chen H, Li S, Liu J et al. (2004) Chronic inorganic arsenic exposure induces hepatic global and individual gene hypomethylation: implications for arsenic hepatocarcinogenesis. Carcinogenesis, 25, 1779-1786.

Chen H, Ke Q, Kluz T, Yan Y, Costa M (2006) Nickel ions increase histone $\mathrm{H} 3$ lysine 9 dimethylation and induce transgene silencing. Molecular and Cellular Biology, 26, 37283737.

Choi IS, Estecio MR, Nagano Y et al. (2007) Hypomethylation of LINE-1 and Alu in well-differentiated neuroendocrine tumors (pancreatic endocrine tumors and carcinoid tumors). Modern Pathology, 20, 802-810.

Clarkson TW, Magos L (2006) The toxicology of mercury and its chemical compounds. Critical Reviews in Toxicology, 36, 609-662.

Dietz R, Heide-Jørgensen M-P, Härkönen T, Teilmann J, Valentin N (1991) Age determination of European harbour seals. Sarsia, 76, 17-21.

Dietz R, Pacyna J, Thomas DJ et al. (1998) Heavy metals. In: Assessment Report: Arctic Pollution Issues - Arctic Monitoring and Assessment Program (AMAP) (eds Wilson SJ, Murray JL, Huntington HP), pp 373-524. Arctic Monitoring and Assessment Program, Os10.

Dietz R, Riget F, Born EW (2000) Geographical differences of zinc, cadmium, mercury and selenium in polar bears (Ursus maritimus) from Greenland. Science of the Total Environment, $245,25-47$.

Dolinoy DC, Weidman JR, Waterland RA, Jirtle RL (2006) Maternal genistein alters coat color and protects Avy mouse offspring from obesity by modifying the fetal epigenome. Environmental Health Perspectives, 114, 567-572.

Eckhardt F, Lewin J, Cortese R et al. (2006) DNA methylation profiling of human chromosomes 6, 20 and 22. Nature Genetics, 38, 1378-1385.

Ernst C, McGowan PO, Deleva V et al. (2008) The effects of $\mathrm{pH}$ on DNA methylation state: In vitro and post-mortem brain studies. Journal of Neuroscience Methods, 174, 123-125.

Esteller M (2007) Cancer epigenomics: DNA methylomes and histone-modification maps. Nature Review Genetics, 8, 286298.

Esteller M (2008) Epigenetics in cancer. New England Journal of Medicine, 358, 1148-1159.

Franceschini MD, Lane OP, Evers DC et al. (2009) The corticosterone stress response and mercury contamination in free-living tree swallows, Tachycineta bicolor. Ecotoxicology, 18, 514-521.

Gabory A, Attig L, Junien C (2009) Sexual dimorphism in environmental epigenetic programming. Molecular and Cellular Endocrinology, 304, 8-18.

Gochfeld M (2007) Framework for gender differences in human and animal toxicology. Environmental Research, 104, 4-21.

Hontela A, Rasmussen JB, Audet C, Chevalier G (1992) Impaired cortisol stress response in fish from environments 
polluted by PAHs, PCBs, and mercury. Archives of Environmental Contamination and Toxicology, 22, 278-283.

Hynd MR, Lewohl JM, Scott HL, Dodd PR (2003) Biochemical and molecular studies using human autopsy brain tissue. Journal of Neurochemistry, 85, 543-562.

Jabbari K, Caccio S, Pais de Barros JP, Desgres J, Bernardi G (1997) Evolutionary changes in CpG and methylation levels in the genome of vertebrates. Gene, 205, 109-118.

Jaenisch R, Bird A (2003) Epigenetic regulation of gene expression: how the genome integrates intrinsic and environmental signals. Nature Genetics, 33(Suppl), 245-254.

Jiang G, Xu L, Song S et al. (2008) Effects of long-term lowdose cadmium exposure on genomic DNA methylation in human embryo lung fibroblast cells. Toxicology, 244, 49-55.

Jirtle RL, Skinner MK (2007) Environmental epigenomics and disease susceptibility. Nature Reviews Genetics, 8, 253-262.

Karimi M, Johansson S, Ekstrom TJ (2006a) Using LUMA: a Luminometric-based assay for global DNA-methylation. Epigenetics, 1, 45-48.

Karimi M, Johansson S, Stach D et al. (2006b) LUMA (LUminometric Methylation Assay) - a high throughput method to the analysis of genomic DNA methylation. Experimental Cell Research, 312, 1989-1995.

Laidre KL, Stirling I, Lowry LF et al. (2008) Quantifying the sensitivity of Arctic marine mammals to climate-induced habitat change. Ecological Applications, 18, S97-S125.

Mill J, Tang T, Kaminsky $Z$ et al. (2008) Epigenomic profiling reveals DNA-methylation changes associated with major psychosis. American Journal of Human Genetics, 82, 696-711.

Orlando EF, Guillette LJ Jr (2007) Sexual dimorphic responses in wildlife exposed to endocrine disrupting chemicals. Environmental Research, 104, 163-173.

Pilsner JR, Liu X, Ahsan H et al. (2007) Genomic methylation of peripheral blood leukocyte DNA: influences of arsenic and folate in Bangladeshi adults. American Journal of Clinical Nutrition, 86, 1179-1186.

Pilsner J, Hu H, Ettinger A et al. (2009) Influence of prenatal lead exposure on genomic methylation of cord blood DNA. Environmental Health Perspectives, 117, 1466-1471.

Reichard JF, Schnekenburger M, Puga A (2007) Long term lowdose arsenic exposure induces loss of DNA methylation. Biochemical and Biophysical Research Communications, 352, 188192.
Robertson KD, Wolffe AP (2000) DNA methylation in health and disease. Nature Review Genetics, 1, 11-19.

Rush SA, Borga K, Dietz R et al. (2008) Geographic distribution of selected elements in the livers of polar bears from Greenland, Canada and the United States. Environmental Pollution, 153, 618-626.

Rusiecki JA, Baccarelli A, Bollati V et al. (2008) Global DNA hypomethylation is associated with high serum-persistent organic pollutants in Greenlandic Inuit. Environmental Health Perspectives, 116, 1547-1552.

Smith LM, Burgoyne LA (2004) Collecting, archiving and processing DNA from wildlife samples using FTA databasing paper. BMC Ecology, 4, 4.

Sonne C, Dietz R, Leifsson PS et al. (2007) Are liver and renal lesions in East Greenland polar bears (Ursus maritimus) associated with high mercury levels? Environmental Health, 6, 11.

Sun H, Zhou X, Chen H, Li Q, Costa M (2009) Modulation of histone methylation and MLH1 gene silencing by hexavalent chromium. Toxicology and Applied Pharmacology, 237, 258-266.

USFWS (2008) Determination of Threatened Status for the Polar Bear (Ursus maritimus) Throughout its Range - Final Rule. pp. 28211-28303. 50 CFR Part 17. Federal Register

Vandegehuchte MB, Kyndt T, Vanholme B et al. (2009a) Occurrence of DNA methylation in Daphnia magna and influence of multigeneration $\mathrm{Cd}$ exposure. Environmental International, 35, 700-706.

Vandegehuchte MB, Lemiere F, Janssen CR (2009b) Quantitative DNA-methylation in Daphnia magna and effects of multigeneration $\mathrm{Zn}$ exposure. Comparative Biochemistry and Physiology Part C Toxicology and Pharmacology, 150, 343-348.

Wang SC, Oelze B, Schumacher A (2008) Age-specific epigenetic drift in late-onset Alzheimer's disease. PLoS ONE, 3, e2698.

Wilson AS, Power BE, Molloy PL (2007) DNA hypomethylation and human diseases. Biochimica et Biophysica Acta, 1775, 138-162.

Nil Basu's research aims to better understand how toxic pollutants affect the health of wildlife, humans, and ecosystems by means of comparative and integrative approaches. 